\title{
Ice cream, blood serum, and other sticky things
}

\section{Sorvete, soro sanguíneo e outras coisas pegajosas}

\author{
Vivette García-Deister \\ Profesora, Facultad de Ciencias/Universidad Nacional Autónoma de México. \\ Ciudad de México - Estado de México - México \\ vivettegarcia@ciencias.unam.mx
}

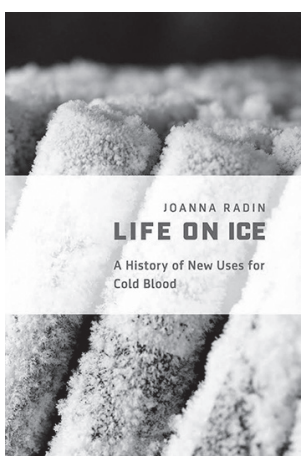

RADIN, Joanna. Life on ice: a history of new uses for cold blood. Chicago: The University of Chicago Press. 2017. 288p.

Tn a time of DNA-centric-historization of biomedical science, Joanna Radin's Life on ice: a history of new uses for cold blood is a cool reminder of the sample behind the data, and of the treatment of samples that preceded (and in some cases, permitted) subsequent extraction of DNA. The book is as much a genealogy of ice cream vending machines and German patents as it is Cold War historiography of scientific diplomacy. Most compellingly, it is a tale of time travel through "freezing, as both a material practice and metaphorical perspective on the limits of life" (p.183). Radin's interconnected analysis of the blood prospecting efforts of John Paul in Alaska, Carleton Gajdusek in Melanesia, Francisco Salzano and James Neel in the Brazilian Amazon, and Albert Damon in the Solomon Islands shows that in making "biological matter mobile across space and time" (p.47), the subjects of these studies became unsuspecting time travelers. But Radin's analysis does not stop there: the moral cost and commercial value of this tremendous scientific feat do not go unexamined.

The book's title is so packed with analytic references that it is worth explaining. Cold blood refers literally to the blood-filled vacutainers kept in cold storage for scientific use, but cold here also qualifies the societies that comprised the population samples from which the blood was extracted. The latter use of the term is an allusion to Claude Lévi-Strauss' depiction of the "primitive" and "geographically isolated" tribes of Mato Grosso, which he described in opposition to his own "hot" society towards the end of the 1960s. Radin takes up this thermodynamic metaphor and mobilizes it further: "As the 1970s began, scientists ... would use the resources at their disposal to intensify efforts to salvage blood from members of 'cold' societies whose purported stability was being thawed - such that it could be preserved in artificially frozen environments" (p.117). We thus learn in this book that cryopreservation practices were set in motion to appease Cold War anxieties which derived from attitudes towards those latitudes where the war was hot. As the lives of these societies were put on ice, so too were the power relations and "colonial hierarchies

http://dx.doi.org/10.1590/S0104-59702018000400017 
that shaped the encounter between scientists and those they wished to study" (p.128, figure caption; see also p.57 and p.110) - preserved in the name of both future study and political order.

Also noteworthy is that the book effectively shows how first-world scientists' eagerness to "accumulate primitives" (p.101) "before it's too late" (p.86) coupled with the techniques and material culture of cryopreservation to produce a blood deluge well before scientists (and science studies scholars, for that matter) could speak of a data deluge. Indeed, "By the mid-1960s it was clear that salvaged blood was being accumulated at a pace that outran scientists' ability, and sometimes desire, to ensure it was processed" (p.127). In this sense, the book posits that contemporary data-intensive science is built upon sampling-intensive science, some produced more than half a century ago. In Radin's narrative, in terms of future-constructing machines, so far the freezer has greatly outperformed the sequencer.

Despite the different political circumstances, ethical considerations, and technologies through which blood was collected and analyzed at that time (and through which its components are being scrutinized now), there is something remarkable and fairly disturbing about the epistemic continuity afforded by this permanency of biological matter. Questions regarding the trade-offs of sample-to-data transformations are not exclusive to contemporary thinkers, of course, but rarely do we hear historical actors voicing concerns such as this one mid-century: "In the search for scientific universals, social realities were reduced to contingent details" (Stanley Diamond, quoted in Radin, 2017, p.108). Or even earlier: "The sample could not on its own yield the requisite data necessary for making sense of epidemics. Analysis, in Paul's view, was to be informed not only by what laboratory tests revealed but by what the individual seeking to draw conclusions had observed with all of his senses" (John Paul quoted in Radin, 2017, p.85). While these opinions suggested limits to the ability of the "cold chain" to connect the field to the lab, Radin shows that in practice, cryopreservation nevertheless brought with it what appeared to be scientific superpowers. In the presence of frozen blood, time travel was possible, "nature's experiments" fell under the purview of serology, uncertainty became valuable, funding became reliable, scientific objectives and political agendas - some of which were "as yet unknown" - were seamlessly aligned.

Blood, literally a connective tissue, thus created an infrastructure for bio-surveillance writ large. Across space and time, accumulated blood allowed things as dissimilar as bovine sperm, liquid nitrogen, a research vessel turned floating freezer, and the World Health Organization to "stick." Keith Guzik (2016, p.15) has recently brought forth the Latin root haereo, meaning "to hang or hold fast, stick, cleave, cling, adhere, be fixed, sit fast, remain close" as part of an analytic that identifies control over the administration of mundane objects as a means for consolidating state authority. Guzik's argument is that surveillance technologies are designed to "make things stick." In a parallel manner, Radin's book teaches us how building on the adhesiveness of blood as synecdoche for social life, scientists' efforts to govern it rendered Cold War anthropological and biomedical science more cohesive to Western Nation-states.

As for the book's place in the contemporary academic scene, it is best described as an intellectual crossover. Built on a solid platform of Cold War historiography of science yet 
combining features that allow it to effortlessly journey into the history of technology, the history of genetics and biomedicine, the history and philosophy of scientific practice, bioethics, science and justice, and critical anthropology of science, this skillfully written book will spike interest in scholars across geographic and disciplinary maps. I anticipate that it will also become a valuable comparative resource for those interested in biobanking efforts and tissue repositories that do not involve blood.

\section{REFERENCES}

GUZIK, Keith.

Making things stick: surveillance technologies and Mexico's war on crime. Oakland, CA: University of California Press. 2016.
RADIN, Joanna.

Life on ice: a history of new uses for cold blood. Chicago: The University of Chicago Press. 2017.

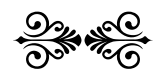

